\title{
A intimidade dos pequenos gestos
}

\section{Nuno Carinhas}

Com um agradecimento especial a Pedro Sobrado

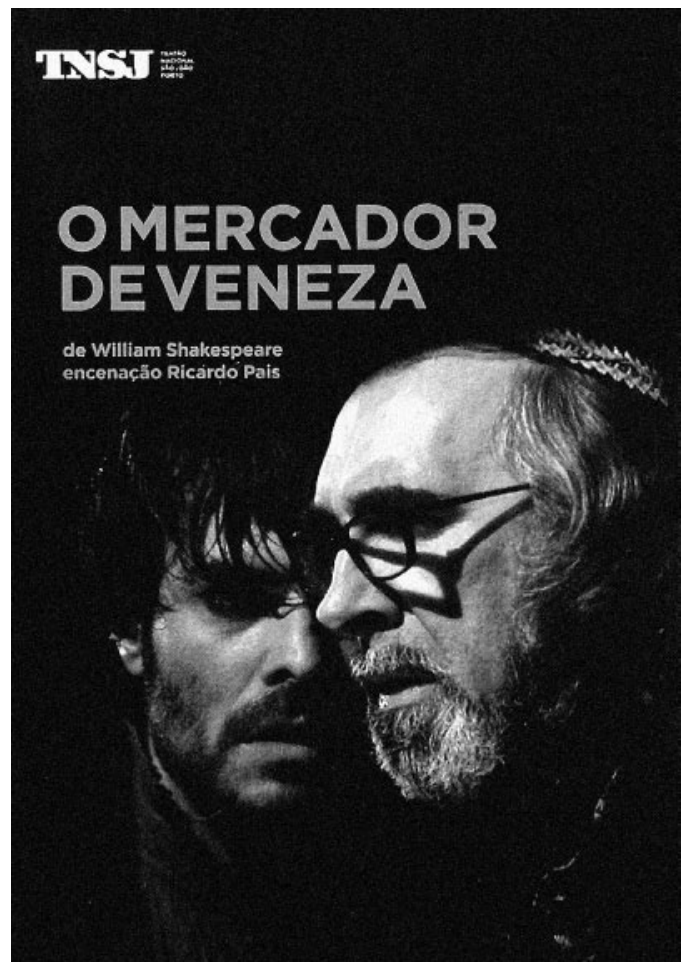

Acho que seria interessante evocar uma espécie de acaso: em Novembro de 2007, Janet Adelman, professora da Universidade da Califórnia, especialista em Shakespeare e - muito curiosamente! - no Paraíso Perdido, de Milton, falou no TNSJ sobre este Mercador de Veneza.

Poucos meses depois de ter publicado Blood Relations: Christian and Jew in The Merchant of Venice (University of Chicago Press, 2008), um livro que voltou a baralhar as coordenadas da posteridade crítica da peça, Janet Adelman assistiu, por três vezes, ao espectáculo do Ricardo Pais. Na conferência, confessou:

A encenação revela (...) uma visão da peça que ficou a repicar dentro de mim, porque é tão mais profunda do que consegui desenvolver em quinze anos de trabalho em torno de 0 mercador. (...) Teria escrito um livro diferente se tivesse visto esta encenação antes. Porquê? Sabemos duas coisas sobre António. Sabemos da sua tristeza e do seu ódio por Shylock. 0 que esta versão me permitiu ver é que a tristeza inexplicável de António não só causa o seu ódio pelo judeu, mas também é causada pelo seu ódio ao judeu. Permitiu-me ver que o custo da divisão interior, de uma divisão deste tipo, é um melancólico sentimento de perda que advém de se ter cortado e vilipendiado uma parte de nós próprios.
Tiago Guedes, $O$ mercador de Veneza (registo integral do espectáculo), Teatro Nacional São João, 2009, 146’ aprox.

Sobre o grande dilema do que se é verdadeiramente no intimo (o tema central da peça, segundo Janet Adelman), há outro passo interessante na conferência:

\footnotetext{
A peça desenvolve uma obsessão com o que está no interior, com aquilo que se é no intimo. Está obcecada com o que se passa dentro de António. Ele começa a peça dizendo "Na verdade não sei por que ando tão triste", e nós não conseguimos deixar de pensar: "Bom, com certeza, ali pelo Acto $V$, vamos perceber porque é que o homem esta triste". Não. Nunca o saberemos, nunca conseguiremos na verdade espreitar para dentro de António. Também os cofres - que nesta encenação deixam de ser entediantes - suscitam a pergunta: o que há dentro deles? A peça pergunta constantemente: "0 que há lá dentro?"
}

A proximidade da câmara ameaça desvendar, captando perigosamente a intimidade dos pequenos gestos. A indiscrição dos grandes planos denuncia as atitudes da espera, da circunspecção e da atenção suspeitosa, sobrepondo a leitura corporizada da expectativa às argumentações tornadas indecentemente próximas, maximizando os pormenores de tudo e de todos envolvidos no universo da intriga.

No palco, estúdio e estádio de chão de teclas ínvias - tecto ilusório retrovertido em lajedo -, assenta o cinema sobre a encenação do mais cinematográfico dos nossos encenadores, aquele que encena com o olhar do movimento dramatúrgico lento, de travellings e de gruas de sentido. Aquele que corta e cola à vista, pelo movimento e pela luz, passando de lugares no mesmo lugar.

É sobre a beleza secreta de tudo, cuja proximidade não consegue revelar o insondável, mas que sonda e insiste na sua possivel revelação, que as câmaras de Tiago Guedes nos surpreendem pelo uso caleidoscópico assente numa montagem que reinventa a coreografia desenhada na cena por Ricardo Pais.

Dá-nos a ver as possibilidades das argumentações num imparável jogo de simultaneidades do olhar voluptuoso que testemunha e documenta. Este é um documentário sobre o interior da intriga ficcional, um objecto único e surpreendente da apropriação. Um retrato em movimento das vidas postas em jogo por uma ficção sobre a pudicícia dos afectos.

Cumpre-se o vinculo e a vitória de dois criadores, dois olhares cruzados, tal como os olhares de António e Shylock.
Apresentação feita a 1 de Novembro de 2009, por ocasião da abertura ao público do Centro de Documentação do Teatro Nacional São João no Mosteiro de São Bento da Vitória, no Porto, quando se lançou este DVD.

Nuno Carinahas é encenador, cenógrafo figurinista, e é actualmente 0 Director Artístico do Teatro Nacional São João. 
O mercador de Veneza de William Shakespeare, enc. Ricardo Pais, TNSJ, 2008 (Albano Jerónimo)

fot. João Tuna.

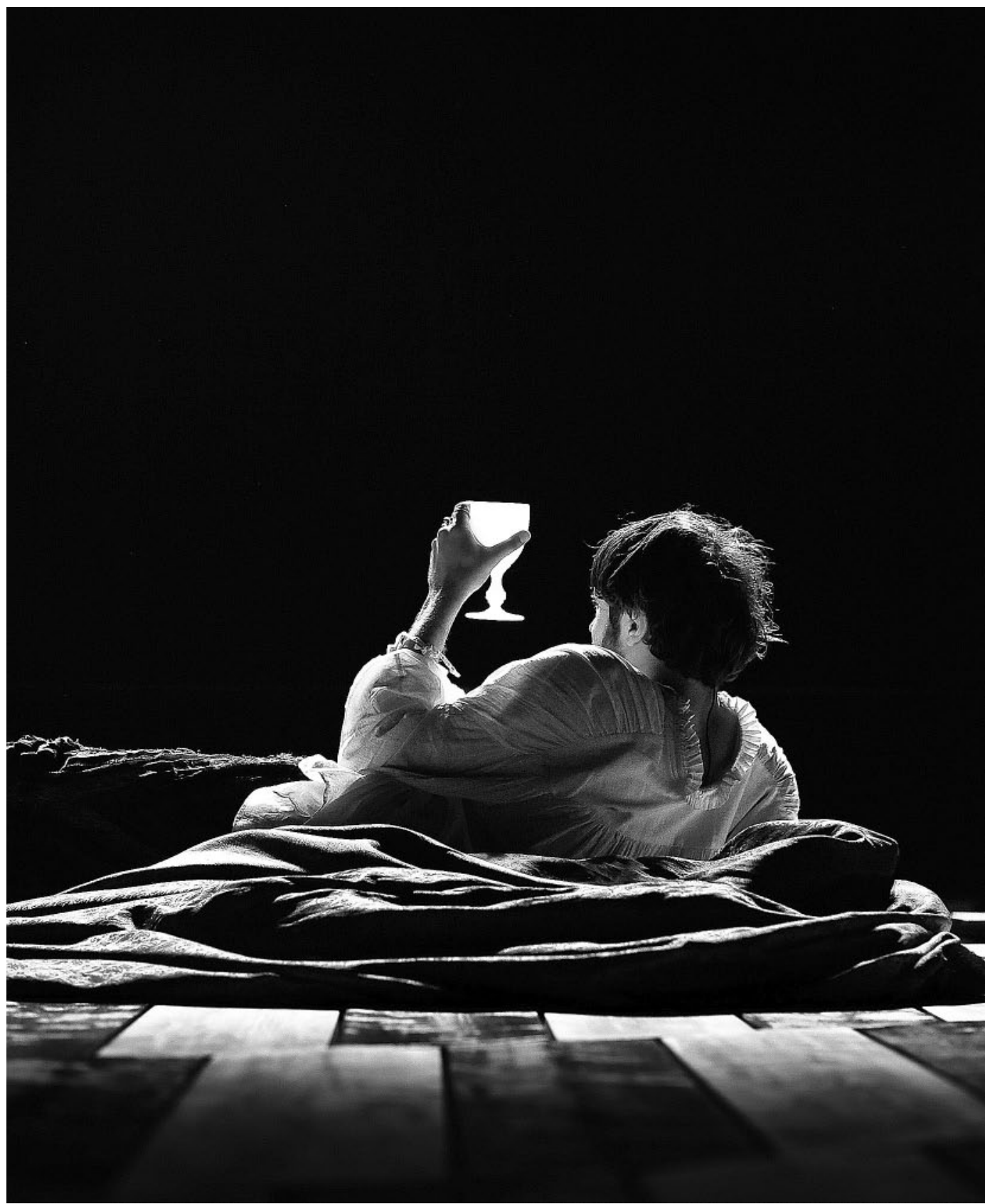

E a pergunta persiste: "o que há lá dentro?". Este é um objecto sobre a pele, a pele de todas as coisas postas em segredo pelos sujeitos desejantes. Um registo que ilumina e revela até ao limite a interioridade do não-dito.

Ao filmar uma obra que insiste tanto na ideia de golpe corte ou incisão, Tiago Guedes opta frequentemente por cindir o ecrã em duas metades desiguais. Com este recurso que a alguns parecerá aleatório ou ocioso, Tiago Guedes evoca, reproduz, explora e prolonga no filme os assimétricos dualismos que informam a obra (texto e espectáculo): cristão/judeu, Veneza/Belmonte, interioridade/exterioridade, masculino/feminino, António/Shylock. Ao mesmo tempo, uma tal cisão faz lembrar a leitura do encenador, para quem "a peça é toda sobre a ambivalência, ou melhor, as ambivalências deste mundo".

Sabemos que 0 mercador de Veneza é uma obra obcecada com aquilo que está dentro, com o que se é verdadeiramente no íntimo. Se fosse necessário, a invenção da rêverie, do pesadelo auschwitziano de António, prova que essa instigante obsessão é não apenas da peça, mas também do espectáculo. Desde a primeira declaração queremos aceder ao coração de António para compreender o mistério da sua tristeza. Tragicamente, Shylock quase fará esse favor ao espectador - ao próprio António que tanto deseja abrir-se, "coração e bolsa", a Bassânio.

A realização de Tiago Guedes - sem violência nem golpes subversivos - serve uma ideia de espectáculo, a de Ricardo Pais, abrindo-nos caminho para o seu interior, conduzindonos para o seu íntimo.

Termino, citando a personagem de Solânio para me referir a este trabalho com uma dupla assinatura, a de Ricardo Pais e Tiago Guedes: "Aqui nos despedimos. Deixamo-vos agora em melhor companhia". 